\title{
The effective modes of infrared radiators and heating systems
}

\author{
Elena Ptitsyna ${ }^{1}$, Alexander Kuvaldin², and Dmitry Ptitsyn ${ }^{1, *}$ \\ ${ }^{1}$ Omsk State Technical University, Omsk, Russian Federation \\ ${ }^{2}$ National Research University “Moscow Power Engineering Institute”, Moscow, Russian Federation
}

\begin{abstract}
The authors have been researching the effect of polyharmonic currents (complex waveform current) on the characteristics of different types of radiators for a few years. These researches have shown an increase in the energy efficiency of installations with dark and light radiators and the ability to control the harmonic composition of radiation. It is important considering the need to harmonize the frequency characteristics of a radiator with the frequency response of an energy absorbing surface. The object of experimental research are flexible heating tape and installations with dark radiators and their joint operation modes when powered by complex waveform current from a common power source. The purpose of the work is the definition of characteristics of the flexible heating tape and dark infrared radiators when changing the amplitude and frequency of the supply voltage to develop recommendations for the selection of effective modes.
\end{abstract}

\section{Introduction}

The problems of electric energy losses reduction and improving the efficiency of electric grid complex are priority direction of the Russian Federation state policy. In $[1,2,3]$ it is proved that the losses of electrical energy in overhead lines depend on the temperature: temperature is important factor determining the loadpower losses in overhead lines.

In $[4,5]$ it is determined that in electric industrial networks the increased power and energy losses is due to higher current harmonics when the share of nonlinear load increases.

An increased load on neutral wire in three-phase electric networks with asymmetric and nonlinear consumers leads to a phase misalignment in voltage and termination of power supply $[6,7]$. Various devices for electric heating are used in oil refineries: submersible heaters, flange submersible heaters, flow electric heaters, duct air heaters. Modern electric heaters are available up to $5 \mathrm{MW}$, for heating temperatures up to $800^{\circ} \mathrm{C}$, operating at pressures up to $25 \mathrm{MPa}$. Modern heating systems can use a resistive cable, skin system or self-regulating cable with various insulations: InWarm Wool, In Warm Foam, InWarm Flex [8]. Application of the skin-system - core inductors and induction-resistive heating system (IRHS) required the development of calculation methods of power losses in alternating magnetization of steel at a frequency of $50 \mathrm{~Hz}$, that is, the hysteresis loss [9].

Thus, not only higher harmonics [4-7], temperature, humidity [1-3], as well as hysteresis losses and eddy currents [6-7], the level of supply voltage and the type of current affect the efficiency of electrical networks [1-7] and individual electrical devices [6-7]. Losses of active power at alternating current of $50 \mathrm{~Hz}$ frequency increase in comparison with losses at direct current due to surface effect and proximity effect [10].

In electrotechnology, on the contrary, the reduced or increased frequency current, pulse current, complex waveform current (CWC) with constant component and without it (harmonic spectrum) is used to obtain positive electrical and technological effects at high temperatures of electrolytes melts $950-960^{\circ} \mathrm{C}$ and for arc discharges in the small capacity melting furnaces of direct and indirect heating, in furnaces firing green blanks and graphitization [11].

It is experimentally proved $[12,13]$, in the resistance electric furnaces of direct and indirect heating, improving the efficiency is also possible due to improvement of an electric mode with CWC.

Infrared heating installations are used for space heating, drying of paint coatings, grain drying, processing of biological objects, heat treatment of welds, etc. Works $[14,15]$ proved that the mechanical characteristics of the weld, heat generation in the metal depend on the electric arc and cause subsequent deformation. Improving the quality of welds is achieved by subsequent heat treatment [16].

A review of the literature confirms the relevance of the use of infrared heating installations. They are a kind of electric resistance furnaces $[17,18]$ and heating systems $[8,9]$. The values of efficiency coefficient and the power factor are used to evaluate the energy efficiency of their work, while the efficiency of 
installations depends on the power losses in radiator, power source and technological link.

Other works have found that the radiation intensity increases when a high-frequency alternating current flows through the radiating element due to the force action of the electromagnetic field on charged particles (electrons and ions) of the material. It has shown in the works of G. N. Rokhlin [19], V. Filkenburg and G. Mecker [20], O. A. Popov and S. A. Svitnev [21].

This phenomenon is like to field emission from the cathode surface combined with thermionic emission.

Works [12, 13] have shown the ability to increase the energy efficiency of installations with dark and light radiators and to control the harmonic composition of radiation. It is important in view of the need to harmonize the frequency characteristics of radiator with the frequency response of energy absorbing surface.

However, the literature does not reflect the influence of complex waveform current on the efficiency of electrical devices such as electric heating devices and dark heaters.

This paper presents the researches results of joint operation of installations with infrared radiators and electric heating systems when powered by CWC from a common source.

The purpose of the paper is research of the energy parameters in the mixed-load connection node with the flexible heating tape and the dark infrared heater when powered by complex waveform current to select the effective modes. For achievement of the purpose, the authors solved the next scientific problems: development of the methodology for research of the mixed load when power by CWC in a stationary state after switching, transition process and development of recommendations for choice of the effective modes necessary for synthesis of the functioning algorithm for an automatic control system.

\section{Methods}

The main research objects are the flexible heating tape and the dark infrared radiator. The main parameters and sizes of the flexible heating tape: voltage $-220 \mathrm{~V}$, nominal power $-0.05 \mathrm{~kW}$, heater length $-2.6 \mathrm{~m}$, width $23 \mathrm{~mm}$, thickness $-3.3 \mathrm{~mm}$, limiting temperature on the surface $-60^{\circ} \mathrm{C}$, specific heat $-40 \mathrm{~W} / \mathrm{m}$. The main parameters and sizes of the radiator:

Flexible heating tapes are used for protection from freezing, heating and heat loss compensation of pipelines of heat exchangers, tanks etc. They are allowed to exploitation in the fire-proof installations.

For research, the authors used the dark IR radiators "Nomakon" type of IRS-203-0.1/230-2 power of $100 \mathrm{~W}$ with the radiation surface of $60 \times 60 \mathrm{~mm}$.

The presented results were made in comparison of four electrical modes: normal mode with a current supply of $50 \mathrm{~Hz}$, new mode when direct current supply and new mode when complex waveform current supply without constant component because the rectified current (its constant component) causes water electrolysis. In the normal mode the mixed-load power supply was carried out from a single-phase transformer 220/110V with switching voltage without excitation A-X1, A-X3. In the second mode, power supply was carried out from the single-phase transformer and a rectifier bridge. In the third and fourth modes a choke was used for regulation of current waveform.

In the work, the authors used the following instruments:

- Fiber optic spectrometer AvaSpec-ULS2048-USB2 with software AvaSoft-ALL.

- Analyzer of electric energy quality ANALYST 2060 was used for measurement of electrical parameters.

- Thermal imager Testo 885-2 for measure the temperature. The thermal imager visualized IR radiation (radiation power) from each point and non-contact to measure the surface temperature.

Figure 1 shows the functional scheme of the lab installation powered by CWC without direct component that used for research of load with dark IR radiators and flexible heating tapes. For research the normal mode of the installation, the choke was excluded from the scheme.

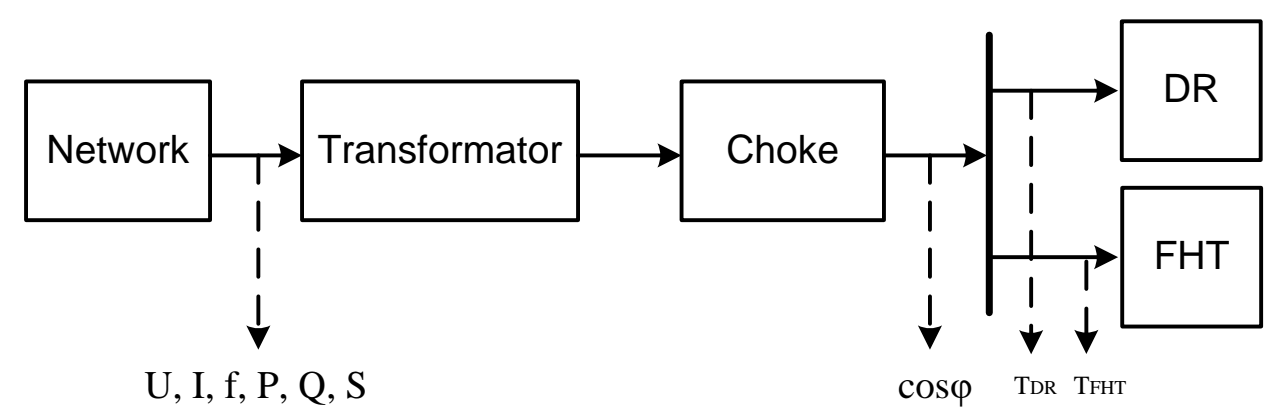

Fig. 1. The functional scheme of the lab installation for research the mode powered by CWC: DR - dark IR radiator; FHT - flexible heating tape. 


\section{Results and Discussion}

Table 1 presents the experimental results for four electrical modes: normal mode and tree new modes.
Figures 2-3 show the thermogram windows with supply voltage of the load $115 \mathrm{~V}$ and $116 \mathrm{~V}$ in 10 minutes of heating in the normal mode: the flexible heating tape and the dark infrared radiator are turned on.

Table 1. The experimental results for the normal and new electrical modes.

\begin{tabular}{|c|c|c|c|c|}
\hline \multirow{2}{*}{ Electrical mode } & \multicolumn{3}{|c|}{ Network power } & \multirow{2}{*}{ Power factor } \\
\hline & Active, kW & Reactive, kVar & Full, kVA & \\
\hline $\begin{array}{c}\text { Normal mode: } \\
\text { alternating current, } 50 \mathrm{~Hz} \\
-116 \mathrm{~V} \\
-115 \mathrm{~V} \\
\end{array}$ & $\begin{array}{l}0.052 \\
0.050\end{array}$ & $\begin{array}{l}0.102 \\
0.091 \\
\end{array}$ & $\begin{array}{l}0.114 \\
0.104\end{array}$ & $\begin{array}{l}0.46 \\
0.48\end{array}$ \\
\hline $\begin{array}{c}\text { New mode: } \\
\text { - direct current } 115 \mathrm{~V} \\
\text { - complex waveform current } \\
\text { with direct component } 115 \mathrm{~V} \\
\text { - complex waveform current } \\
\text { without direct component } \\
115 \mathrm{~V}\end{array}$ & $\begin{array}{l}0.051 \\
0.043 \\
0.045\end{array}$ & $\begin{array}{l}0.101 \\
0.021 \\
0.019\end{array}$ & $\begin{array}{l}0.113 \\
0.048 \\
0.049\end{array}$ & $\begin{array}{l}0.451 \\
0.900\end{array}$ \\
\hline
\end{tabular}

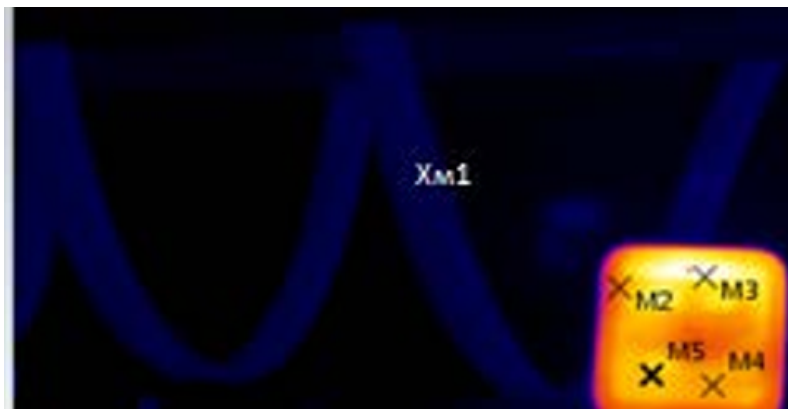

Fig. 2. Thermogram window of load for the physical model of installation with flexible heating tape and dark infrared radiator in the normal mode in 10 minutes heating (load voltage $115 \mathrm{~V}$, temperature at the points $\mathrm{M} 1-31.1^{\circ} \mathrm{C}, \mathrm{M} 2-127.8^{\circ} \mathrm{C}$, $\mathrm{M} 3-166.8{ }^{\circ} \mathrm{C}, \mathrm{M} 4-135.4{ }^{\circ} \mathrm{C}, \mathrm{M} 5-143.2^{\circ} \mathrm{C}$ )

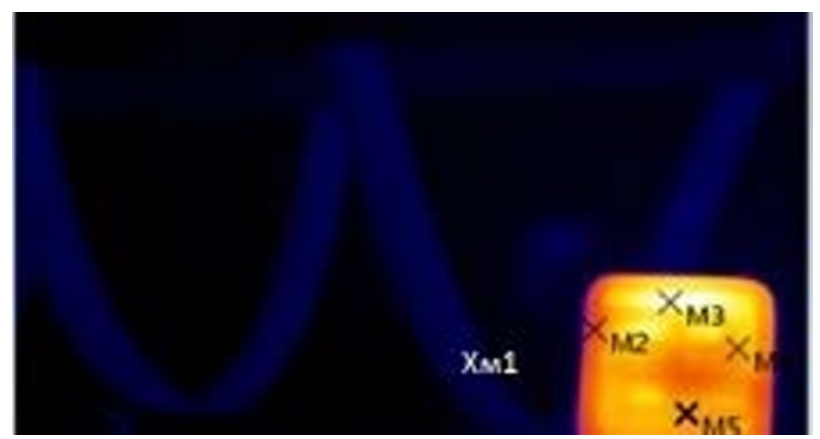

Fig. 3. Thermogram window of load for the physical model of installation with flexible heating tape and dark infrared radiator in the normal mode in 10 minutes heating (load voltage $116 \mathrm{~V}$, temperature at the points $\mathrm{M} 1-32.7^{\circ} \mathrm{C}, \mathrm{M} 2-113.7^{\circ} \mathrm{C}$, $\mathrm{M} 3-174.9^{\circ} \mathrm{C}, \mathrm{M} 4-144.2^{\circ} \mathrm{C}, \mathrm{M} 5-142.0^{\circ} \mathrm{C}$ )

Figure 4 shows the thermogram window for the mixed load for 10 minutes of temperature rise when powered by direct current.

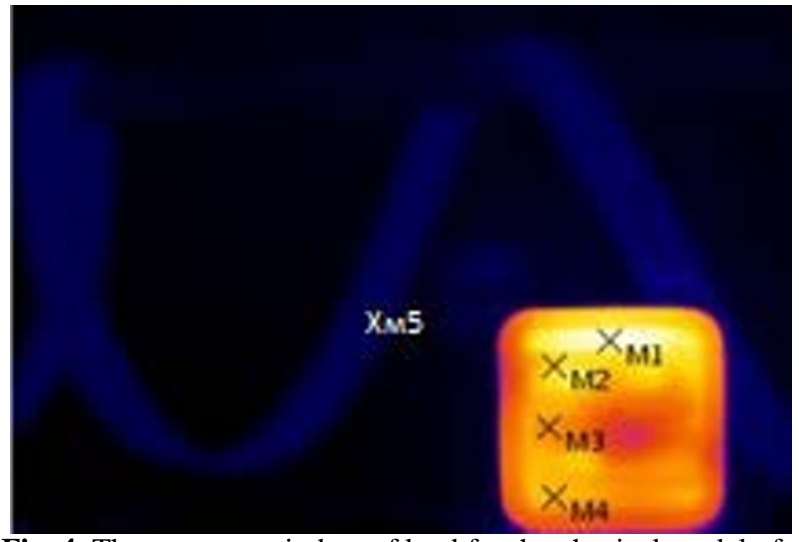

Fig. 4. Thermogram window of load for the physical model of installation with flexible heating tape and dark infrared radiator in the new mode in 10 minutes heating: direct current supply (temperature at the points $\mathrm{M} 1-142.2^{\circ} \mathrm{C}, \mathrm{M} 2-129.3^{\circ} \mathrm{C}$, M3 $112.9^{\circ} \mathrm{C}, \mathrm{M} 4-120.3^{\circ} \mathrm{C}, \mathrm{M} 5-32.2^{\circ} \mathrm{C}$ )

Figure 5 shows the thermogram window for the mixed load for 10 minutes of temperature rise when complex waveform current supply.

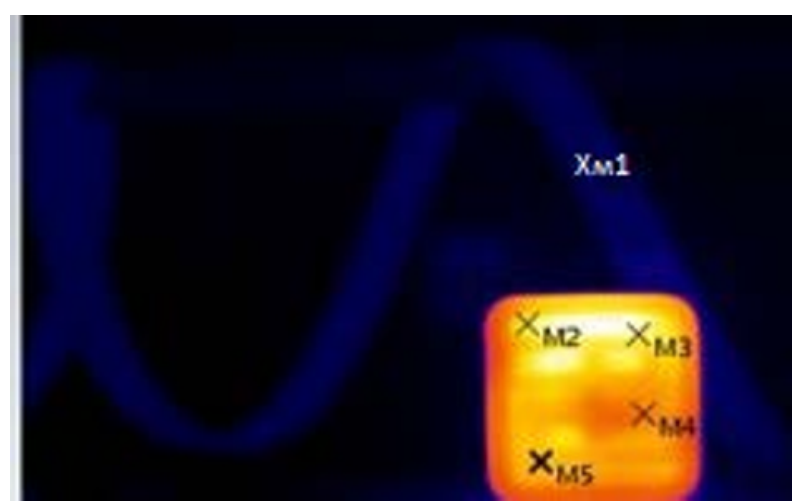

Fig. 5. Thermogram window of load for the physical model of installation with flexible heating tape and dark infrared radiator in the new mode in 10 minutes heating: complex waveform current with direct component (the temperature at the points $\mathrm{M} 1-34.5^{\circ} \mathrm{C}, \mathrm{M} 2-166.6^{\circ} \mathrm{C}, \mathrm{M} 3-172.0^{\circ} \mathrm{C}, \mathrm{M} 4-134.1^{\circ} \mathrm{C}$, M5 $\left.-151.1^{\circ} \mathrm{C}\right)$ 
Figures 6 shows the thermogram windows for the mixed load when complex waveform current supply without direct component in 10 minutes heating.

Table 2 presents the temperature of the flexible heating tape in 1, 3, 5, 7 and 10 minutes heating when the mixed load powered by complex waveform current without direct component.

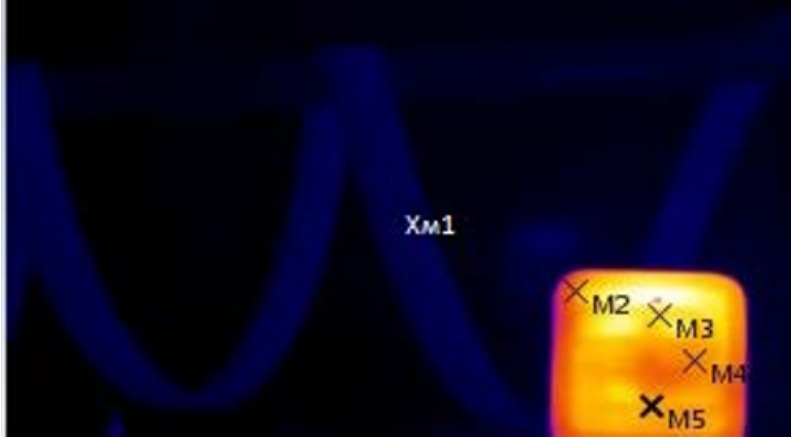

Fig. 6. Thermogram window of load for the physical model of installation with flexible heating tape and dark infrared radiator in the new mode in 10 minutes heating: $\mathrm{M} 1-33.9^{\circ} \mathrm{C}, \mathrm{M} 2-$ $139.9^{\circ} \mathrm{C}, \mathrm{M} 3-163.2^{\circ} \mathrm{C}, \mathrm{M} 4-138.6^{\circ} \mathrm{C}, \mathrm{M} 5-146.2^{\circ} \mathrm{C}$

Table 2. The rate of temperature rise when powered by complex waveform current without direct component

\begin{tabular}{|c|c|c|c|}
\hline Times, s & Voltage, $\mathbf{V}$ & $\begin{array}{c}\text { Initial } \\
\text { temperature, } \\
{ }^{{ }^{\circ} \mathbf{C}}\end{array}$ & $\begin{array}{c}\text { Final } \\
\text { temperature, } \\
{ }^{\circ} \mathbf{C}\end{array}$ \\
\hline 1 & & & 68.9 \\
3 & & & 102.0 \\
5 & 115 & 25.0 & 145.9 \\
7 & & & 162.7 \\
10 & & & 179.4 \\
\hline
\end{tabular}

\section{Conclusions}

It is experimentally established that when the complex waveform current supply (with constant component and without it) of the flexible heating tape and dark infrared radiator (that is a mixed load), the efficiency of the load increases. In steady-state mode, the effective mode is maintained for each of the mixed loads. The electromagnetic component, along with the temperature component, affects the mobility of charged particles in the electron plasma of the metal. This increases the efficiency of the heating process at the same rate of temperature rise. For the researched mixed load, this is manifested in improving the power factor in the power node: from 0.46 (normal mode at $115 \mathrm{~V}$ ) to 0.900 (new mode - CWC with constant component) and 0.918 (new mode - CWC without constant component).

\section{References}

1. S.S. Girshin, V.N. Gorjunov, A.Y. Bigun, E. V. Petrova and E. A. Kuznetsov E A, Dynamics of Systems, Mechanisms and Machines (Dynamics), IEEE. 1-5 (2016)

2. S.S. Girshin, A.Y. Bigun and E.V. Petrova, 2nd International Conference on Industrial Engineering, Applications and Manufacturing, IEEE. 1-6 (2016)

3. A.Y. Bigun, O.A. Sidorov, D.S. Osipov, S.S. Girshin, V.N. Gorjunov and E.V. Petrova, Journal of Physics: Conference Series, IOP. 1-10 (2018)
4. A.A. Belitskiy, Y.E. Shklyarskiy, A.Y. Shklyarskiy, Proceedings of the 2018 IEEE Russia section young researchers in electrical and electronic engineering conference, ELCONRUS, IEEE. 1012-1015 (2017)

5. A.A. Belitskiy, O.V. Denisova, I.I. Rastvorova, Proceedings of the 2018 IEEE Russia section young researchers in electrical and electronic engineering conference, ELCONTRUS, IEEE. 570-571 (2018)

6. D.S. Osipov, D.V. Kovalenko and N.N. Dolgikh, Dynamics of Systems, Mechanisms, and Machines. Dynamics, IEEE. 1-6 (2017)

7. D.S. Osipov, N.N. Dolgikh, V.N. Goryunov, D.V. Kovalenko, Dynamics of Systems, Mechanisms and Machines. Dynamics, IEEE (2016)

8. A.B. Kuvaldin, M.A. Fedin, M.L. Strupinskiy, N.N. Khrenkov, Asta Technica CSAV. 459-466 (2018)

9. A.B. Kuvaldin, M.L. Strupinskiy, N.N. Khrenkov, Electricity 10, 54-61 (2009)

10. A.B. Kuvaldin, Theory of induction and dielectric heating, Moscow Power Engineering Institute (1999)

11. E.V. Ptitsyna, D.V. Ptitsyn, and A.B. Kuvaldin, Omsk Scientific Bulletin. Series "Devices, machines and technologies" 2, 20-27 (2018)

12. E.V. Ptitsyna Energy and resource saving-XXI century: proceedings of the international scientific and practical Internet conference, Orel. 128-133 2016

13. E.V. Ptitsyna, A.B. Kuvaldin and D.V. Ptitsyn, Electrotechnologies for material processing: XVIII 
International UIE-Congress, Hannover. 497-502 (2017)

14. V.Y. Frolov, A.I. Toropchin, Technical Physics Letters. 41(13), 41-47 (2015)

15. A.I. Toropchin, V.Y. Frolov, A.V. Pipa, R. Kazakov, D. Uhrland, Journal of Physic: Conference Series, IOP. (2014)

16. V.M. Borzakoskij and N.S. Kirpach, Patent, SU1682101A1 (1991)

17. G.D. Luzgin, V.V. Potemin, J.S. Pochivalov, G. V. Avrorov, Patent RF, RU2431793C1 (2011)

18. A.B. Bodyrev, V.V. Vartanov, G.D. Luzgin, Patent RF, RU2355961C1 (2009)

19. G.N. Rokhlin, Discharge light sources, 2nd ed (1991)

20. V. Finkelburg, Electric arcs and thermal plasma (1961)

21. S.A. Svitnev and O.A. Popov, Light and Engineering. 79-82 (2011) 